\title{
Circulating Tumor Cells and Breast Cancer: The Long and Winding Road Behind and Before Us
}

\author{
Jennifer K. Plichta, MD, MS, FACS ${ }^{1,2,3}$ \\ ${ }^{1}$ Department of Surgery, Duke University Medical Center, Durham, NC; ${ }^{2}$ Duke Cancer Institute, Durham, NC; \\ ${ }^{3}$ Department of Population Health Sciences, Duke University Medical Center, Durham, NC
}

In the United States, an estimated 150,000 women or more are living with metastatic breast cancer (MBC). ${ }^{1}$ Although survival for patients with MBC is improving, most patients with MBC still ultimately succumb to the disease, and the median overall survival period for patients with de novo MBC remains shorter than 2.5 years. $^{2}$

The most recent staging guidelines for breast cancer patients from the American Joint Committee on Cancer (AJCC) include not only traditional anatomic factors but also select biologic variables that have predictive value and refine prognostic estimates. ${ }^{3,4}$ However, these variables currently are used only for stratifying patients with nonmetastatic disease, although some clinicians have proposed using similar variables for stratifying even the metastatic population. ${ }^{5}$ Others have reported on the potential of other biomarkers, such as circulating tumor cells (CTCs) and circulating tumor DNA (ctDNA), which also may have predictive and/or prognostic value, particularly for patients with MBC. ${ }^{6}$ However, tissue biopsies of macrometastases still are required frequently to best guide ongoing treatments. Therefore, ongoing studies seek to find a better alternative to these invasive biopsies that will ultimately yield equivalent information regarding potential treatment response, prognosis, or both.

In the current study, Ring et al. ${ }^{7}$ sought to evaluate whether whole transcriptome RNA-Seq of CTCs can serve as a surrogate for biopsies of macrometastases. To achieve

(C) Society of Surgical Oncology 2022

First Received: 16 December 2021

Accepted: 24 December 2021;

Published Online: 4 January 2022

J. K. Plichta, MD, MS, FACS

e-mail: jennifer.plichta@duke.edu this, RNA-Seq was performed on metastatic tumor biopsies, CTCs, and peripheral blood from 19 patients with MBC. Briefly, concordant expression was noted for $78 \%$ of potentially clinically actionable target genes in CTCs and corresponding metastases, and only $4.7 \%$ showed statistically significant discordant expression, suggesting that CTCs could potentially serve as a surrogate for biopsies of distant metastatic sites to identify therapeutic targets. Notably, concordance was much lower for the single nucleotide variant (SNV) analysis.

In a small exploratory analysis, four patients with progressive disease who underwent repeated harvest of CTCs at a second time point were also evaluated, and the data showed changes in biologic features that may have implications for ongoing clinical management. Overall, additional analyses showed a higher number of heterogeneous somatic mutations in CTCs than in macrometastases and an increase in CTC SNVs over time. Furthermore, the authors suggested that RNA-Seq of CTCs was able to detect driver mutations in patients with $\mathrm{MBC}$, which may have implications for patient management.

Importantly, the authors identified several genes with implications for breast cancer patients that were highly expressed in CTCs, and although a high degree of concordance was observed, a notable degree of discordance remained. ${ }^{7}$ The authors further recognize that these differences could be attributable to several factors, such as the origin of the CTCs from various metastatic sites versus the primary tumor, changes in transcriptional programs once the CTCs adapt to new environments, and/or differences in the timing of the metastatic site establishment (remotely vs recently) versus when the CTCs were created (which likely was more recently and potentially more reflective of the most recent genomic alterations and treatments). Further studies are needed to clarify the ideal timing for acquisition of these 
CTC samples. Regardless, these findings also highlight the heterogeneity of breast cancer, not only between different patients, but also within each individual patient.

Others have also explored intra-tumoral heterogeneity in breast cancer. For example, the average discrepancy for the estrogen receptor in particular may be as high as $20 \%,{ }^{8}$ and important alterations such as this are likely related to the treatment resistance patterns that ultimately develop in most patients with MBC. ${ }^{9}$ Unfortunately, although tumor heterogeneity was observed in many of the studies, determining the "gold standard" or which result is most significant/important remains a challenge. More plainly, what do these findings mean for our patients, and how do we apply this information to our daily practices? Ongoing studies to further elucidate the vast heterogeneity that exists in MBC are essential for further clarification of how best to improve treatments, and thus prognosis, for this devastating disease.

When the implications of data derived from analyzing CTCs are considered, it is important to recognize some of the differences between these unique tumor cells and those from other sites such as the primary breast tumor or distant metastatic sites. In particular, CTCs are exposed to numerous stressors in the microenvironment of the blood and subject to immune surveillance mechanisms.

Not surprisingly, the findings from this study and others demonstrate upregulation of potential genomic alterations involved in immune escape. ${ }^{7,10}$ However, how these differences translate into clinical implications are less well understood and require further investigation.

Although the potential of CTCs still is being explored, data derived from tumor biopsies are already routinely used in providing predictive and prognostic information. For example, a 21-gene assay has been shown to have a significant predictive capacity for select patients with earlystage breast cancer. ${ }^{11,12}$ In addition, this type of assay currently is included in the American Joint Committee on Cancer (AJCC) staging guidelines for early-stage breast cancer. ${ }^{3}$ For patients with MBC, other genomic assays, which include comprehensive genomic profiling from tumor tissue, have been shown to identify genetic alterations that may have therapeutic implications. ${ }^{13}$ However, many of these assays require a tissue sample, which may or may not be readily available for every patient, and if available, may or may not represent the current biology of the ongoing disease for patients with MBC who have had some period of survival. Given the availability and utilization of these types of assays based on tissue samples, establishing similar tests using CTCs seems to be a logical next step. Furthermore, information obtained from CTCs also could be used eventually to stratify patients with MBC into distinct prognostic groups based on genomic profiles derived from CTCs.
In summary, Ring et al. ${ }^{7}$ have provided compelling data showing that CTCs require further investigation as a potential tool for determining how to provide the best care for our patients with $\mathrm{MBC}$, while also minimizing the invasiveness of our investigations. Less invasive monitoring is critically needed as treatments continue to expand and survival outcomes continue to improve for patients with MBC. However, questions on how we ultimately will apply the data to our practices remain because the current technology and interpretation of the data are remarkably complex. Whereas identifying important alterations may be the first step, developing the best method for implementation may prove even more challenging.

DISCLOSURE There are no conflicts of interest.

\section{REFERENCES}

1. Mariotto AB, Etzioni R, Hurlbert M, Penberthy L, Mayer M. Estimation of the number of women living with metastatic breast cancer in the United States. Cancer Epidemiol Biomarkers Prev. 2017;26:809-15.

2. Taskindoust M, Thomas SM, Sammons SL, et al. Survival outcomes among patients with metastatic breast cancer: review of 47,000 patients. Ann Surg Oncol. 2021;28:7441-9.

3. Hortobagyi GN, Connolly JL, D'Orsi CJ, Edge SB, Mittendorf EA, Rugo HS, Solin LJ, Weaver DL, Winchester DJ, Giuliano A. 48. Breast. In: Amin MB, Edge SB, Greene FL, Byrd DR, Brookland RK, Washington MK, Gershenwald JE, Compton CC, Hess KR, Sullivan DC, Jessup JM, Brierley JD, Gaspar LE, Schilsky RL, Balch CM, Winchester DP, Asare EA, Madera M, Gress DM, Meyer LR, editors. AJCC Cancer Staging Manual. 8th ed. New York: Springer International Publishing; 2017.

4. Plichta JK, Ren Y, Thomas SM, et al. Implications for breast cancer restaging based on the 8th-Edition AJCC Staging Manual. Ann Surg. 2018;271:169.

5. Plichta JK, Thomas SM, Sergesketter AR, et al. A Novel staging system for de novo metastatic breast cancer refines prognostic estimates. Ann Surg. 2020. https://doi.org/10.1097/SLA. 0000000000004231.

6. Banys-Paluchowski M, Fehm TN, Grimm-Glang D, Rody A, Krawczyk N. Liquid biopsy in metastatic breast cancer: current role of circulating tumor cells and circulating tumor DNA. Oncol Res Treat. 2021. https://doi.org/10.1159/000520561.

7. Ring A, Campo D, Porras TB, et al. Circulating tumor cell transcriptomics as biopsy-surrogates in metastatic breast cancer. Ann Surg Oncol. 2021. https://doi.org/10.1245/s10434-021-1113 $5-2$.

8. Roulot A, Héquet D, Guinebretière JM, et al. Tumoral heterogeneity of breast cancer. Ann Biol Clin Paris. 2016;74:653-60.

9. Barzaman K, Karami J, Zarei Z, et al. Breast cancer: biology, biomarkers, and treatments. Int Immunopharmacol. 2020;84:106535.

10. Steinert G, Schölch S, Niemietz T, et al. Immune escape and survival mechanisms in circulating tumor cells of colorectal cancer. Cancer Res. 2014;74:1694-704.

11. SparSparano JA, Gray RJ, Makower DF, Pritchard KI, Albain KS, Hayes DF, Geyer CE Jr, Dees EC, Goetz MP, Olson JA Jr, Lively T, Badve SS, Saphner TJ, Wagner LI, Whelan TJ, Ellis MJ, Paik S, Wood WC, Ravdin PM, Keane MM, Gomez Moreno HL, Reddy PS, Goggins TF, Mayer IA, Brufsky AM, Toppmeyer DL, Kaklamani VG, Berenberg JL, Abrams J, Sledge GW Jr. 
Adjuvant chemotherapy guided by a 21 -gene expression assay in breast cancer. $N$ Engl J Med. 2018;379(2):111-21. https://doi.org/ 10.1056/NEJMoa1804710.

12. Kalinsky K, Barlow WE, Gralow JR, et al. 21-Gene assay to inform chemotherapy benefit in node-positive breast cancer. $N$ Engl J Med. 2021;385:2336-47.
13. André F, Ciruelos E, Rubovszky G, et al. Alpelisib for PIK3CAmutated, hormone receptor-positive advanced breast cancer. $N$ Engl J Med. 2019;380:1929-40.

Publisher's Note Springer Nature remains neutral with regard to jurisdictional claims in published maps and institutional affiliations. 